\title{
Taxa de cobertura verde e exportação de macronutrientes pelo capim Marandu em função da aplicação de gesso
}

\author{
Clarice Backes, C.; Marques Santos, A.J.; Vicente de Bessa, S.; Ribon, A.A.; Teodoro, A.G.; Rodrigues, L.M.@; Tomazelo, \\ D.A. e Ferreira Leite, L.L.
}

Universidade Estadual de Goiás. Goiás. Brasil.

\section{PalaVRAS ChaVE ADICIONAIS}

Urochoa brizantha.

Condicionador de solo.

Adubacão química.

Solos do Cerrado.

Produtividade.

\section{RESUMO}

Objetivou-se com este trabalho avaliar a influência do gesso na taxa de cobertura verde do solo pela forragem e a exportação de nutrientes em função das doses aplicadas. O experimento foi conduzindo em campo nos anos de 2012 a 2014 na Fazenda Escola da Universidade Estadual de Goiás, Câmpus São Luís de Montes Belos/GO. O delineamento experimental utilizado foi o de blocos ao acaso, com seis tratamentos e quatro repeticões. Os tratamentos foram constituídos por quatro doses de gesso $(450,900,1800$ e $3600 \mathrm{~kg} / \mathrm{ha})$ e mais dois tratamentos adicionais: um controle (sem gesso e adubação) e um tratamento que recebeu somente a adubação química. Os tratamentos com gesso também receberam a adição de fertilizantes. $O$ gesso promoveu aumento da taxa de cobertura verde do solo pela forrageira, principalmente no período da seca. A ordem decrescente de extração para o capim-marandu, considerando extração máxima de cada nutriente, foi: $\mathrm{K}>\mathrm{N}>\mathrm{Mg}>\mathrm{Ca}>\mathrm{P}>\mathrm{S}$. Para uma produção média de $10 \mathrm{t} / \mathrm{ha} \cdot$ ano do capim Marandu necessita-se de 146, 13, 179, 31, 32 e 14 kg/ha de N, P, K, Ca, Mg e S, respectivamente.

\section{Green coverage rate and exportation of macronutrients by Marandu grass in function of phosphogypsum application}

\section{SUMMARY}

\section{ADDITIONAL KEYWORDS}

Urochoa brizantha.

Soil conditioner.

Chemical fertilization.

Cerrado Soil.

Productivity.

\section{INFORMATION}

\section{Cronología del artículo.}

Recibido/Received: 15.02.2017

Aceptado/Accepted: 15.03.2018

On-line: 15.04 .2018

Correspondencia a los autores/Contact e-mail:

lucasmrzoo@gmail.com

\section{INTRODUÇÃO}

As pastagens do gênero Urochloa foram inicialmente introduzidas do continente africano e com grande adaptabilidade aos solos fracos e ácidos do Cerrado brasileiro, foram difundidas por todo país, tornando-se de grande importância para atividade pecuária (Valle et al., 2009). Ao longo dos anos adotou-se um modelo de exploração baseado na ausência de correção e de reposição dos nutrientes extraídos pela forrageira (Guelfi et al., 2013), resultando em baixos índices de produção, distanciando-se do seu verdadeiro potencial produtivo (Silva et al., 2013), levando a estádios de degradação.

De acordo com Sousa et al. (2016), o fenômeno da acidificação dos solos ocorre devido a remoção de cátions básicos do complexo de troca que são substituídos por cátions de natureza ácida, como alumínio trocável e hidrogênio não dissociado. A acidez encontrada nos solos é prejudicial para o desenvolvimento da forrageira, causando limitação da produtividade independendo do período do ano. Guelfi et al. (2013) verificaram menor 
desenvolvimento radicular e da parte aérea do capim Marandu em solo sem correção, que além de ter $\mathrm{pH}$ ácido $(4,4)$ apresentava também baixos teores de cálcio e magnésio e elevada saturação por alumínio.

Problemas de acidificação do solo podem ser corrigidos pela calagem, que além de neutralizar a acidez do solo fornece cálcio e magnésio. Entretanto, a correção da acidez restringe-se à camada superficial do solo, não solucionando os problemas das camadas inferiores, que de maneira geral, apresentam baixa saturação por bases e alta por alumínio, limitando o crescimento de raízes (Echart e Cavalli-Molina, 2001; Guelfi et al., 2013). Portanto, a identificação de alternativas que possibilitem a melhoria das propriedades químicas do solo em profundidade em pastagens instaladas, partindo da aplicação superficial, sem incorporação, pode viabilizar a permanência e o sucesso deste sistema. A utilização do gesso pode ser uma alternativa para melhoria do ambiente radicular em profundidade (Santos et al., 2006). Por ser um produto mais solúvel é incorporado de maneira fácil ao perfil do solo (Lopes e Guilherme, 2000), proporcionando aumento no suprimento de cálcio e redução da toxidez de alumínio no subsolo (Raij et al., 1998), além do fornecer enxofre para as plantas (Vitti et al., 2008).

A utilização do gesso, por proporcionar maior desenvolvimento do sistema radicular, buscando água em camadas mais profundas, pode ser uma alternativa para aumentar a capacidade de produção no período de estiagem, mantendo a pastagem mais verde. De acordo com Sousa et al. (2016), o maior desenvolvimento do sistema radicular proporcionado pela aplicação do gesso, permite também que as plantas utilizem com maior eficiência os nutrientes aplicados no solo. Essa extração de nutrientes do solo está associada diretamente a capacidade produtiva da cada forrageira, e a reposição desses é de fundamental importância para evitar a degradação e redução da produtividade das mesmas (Costa et al., 2008).

Maiores conhecimentos sobre a extração de nutrientes minerais pelas forrageiras vai permitir o uso mais adequado de adubações (Costa et al., 2010a) e associações das mesmas com práticas corretivas, possibilitando maiores rendimentos e eficiência no uso dos recursos aplicados.
Dessa forma, objetivou-se com este trabalho avaliar a influência do gesso agrícola na taxa de cobertura verde do solo pela forragem e a exportação de nutrientes em função das doses aplicadas.

\section{MATERIAL E MÉTODOS}

O experimento foi conduzindo a campo em pastagem estabelecida de Urochloa brizantha na Fazenda Escola da Universidade Estadual de Goiás, Câmpus São Luís de Montes Belos/GO, a $579 \mathrm{~m}$ de altitude, $16^{\circ} 31^{\prime} 30^{\prime \prime}$ de latitude sul e $5022^{\prime} 20^{\prime \prime}$ de longitude oeste. A pastagem vinha sendo cultivada a mais de 10 anos sem a adoção de manejos adequados, principalmente de reposição de nutrientes extraídos, apresentando sinais de degradação.

O período de avaliação da forrageira foi de outubro de 2012 a setembro de 2014, compreendendo dois anos de avaliação. Nesse período, foram registradas as temperaturas médias, máximas e mínimas e as precipitações pluviais, conforme apresentado na Figura 1.

O solo da área experimental foi classificado como LATOSSOLO VERMELHO DISTRÓFICO (Embrapa, 2013), que no início do experimento apresentou os seguintes atributos químicos: Camada de 0,00-0,20 m - $\mathrm{pH}\left(\mathrm{CaCl}_{2}\right)$ de 5,2; $39 \mathrm{~g} \mathrm{dm}^{-3}$ de M.O.; $6 \mathrm{mg} \mathrm{dm}^{-3} \mathrm{de}$ P (resina); 28; 3,7; 23 e 8 mmol $_{c} \mathrm{dm}^{-3} \mathrm{de}^{+}+\mathrm{Al}^{+3}, \mathrm{~K}, \mathrm{Ca}$ e $\mathrm{Mg}$, respectivamente; saturação por bases (V) de $55 \% ; 6 \mathrm{mg} \mathrm{dm}^{-3}$ de S; Camada de 0,20-0,40 m - pH $\left(\mathrm{CaCl}_{2}\right)$ de 5,2; $29 \mathrm{~g} \mathrm{dm}^{-3}$ de M.O.; $5 \mathrm{mg} \mathrm{dm}^{-3}$ de P (resina); 32; 2,6; 11 e $4 \mathrm{mmol}_{\mathrm{c}} \mathrm{dm}^{-3}$ de $\mathrm{H}^{+}+\mathrm{Al}^{+3}, \mathrm{~K}, \mathrm{Ca}$ e $\mathrm{Mg}$, respectivamente; saturação por bases (V) de $50 \% ; 4 \mathrm{mg} \mathrm{dm}^{-3}$ de S.

Para definição das doses de gesso foi feita uma amostragem de solo na camada de 0-20-0,40 m de profundidade para determinação da análise química e teor de argila que foi de $360 \mathrm{~g} \mathrm{~kg}^{-1}$. A fórmula utilizada foi a seguinte: DG $(\mathrm{kg} / \mathrm{ha})=5,0^{*}$ argila $\left(\mathrm{g} \mathrm{kg}^{-1}\right)$, onde DG = dose de gesso, de acordo com Sousa e Lobato (2004).

O delineamento experimental utilizado foi o de blocos ao acaso, com seis tratamentos e quatro repetições. Os tratamentos foram constituídos por quadro doses de gesso $(450,900,1800$ e $3600 \mathrm{~kg} / \mathrm{ha}$ correspondente a $25,50,100$ e
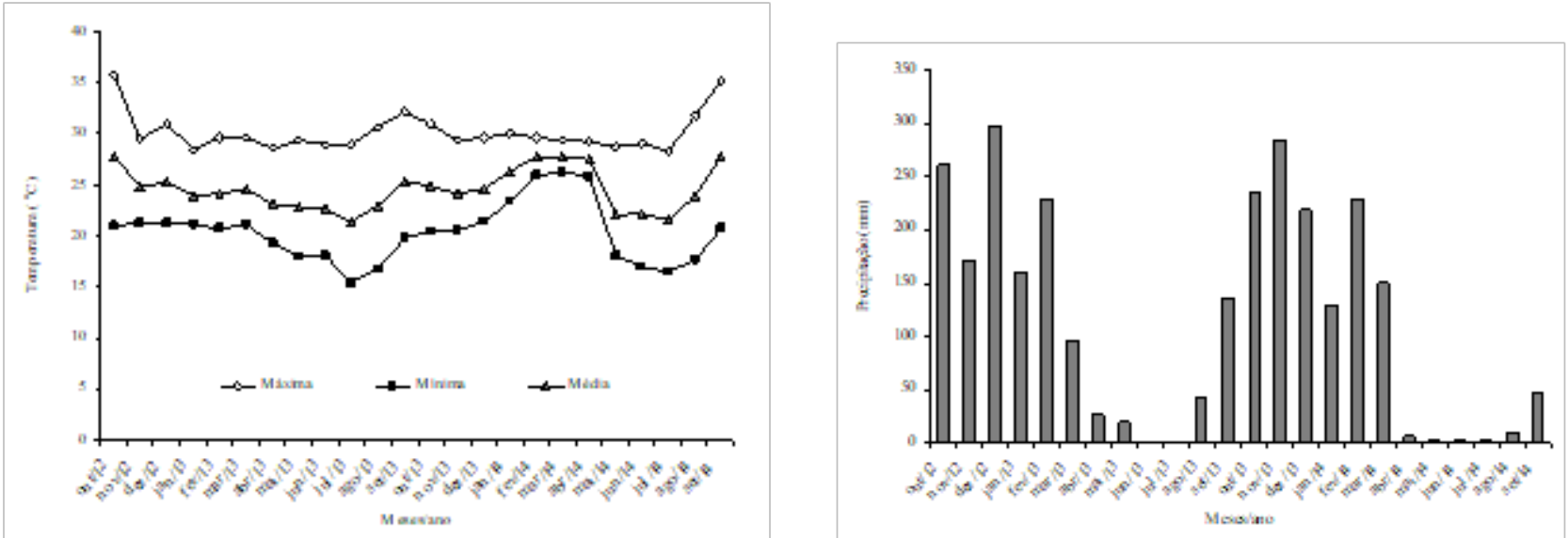

Figura 1. Dados de temperatura média, máxima e mínima e precipitações pluviométricas ocorridas durante a condução do experimento. Outubro de 2012 a setembro de 2014. São Luís de Montes Belos/Goiás (Data of mean, maximum and minimum temperature and precipitations occurring during the conduct of the experiment. October 2012 to September 2014. São Luís de Montes Belo/Goiás). 
200\% do recomendado) e mais dois tratamentos adicionais: um controle (sem gesso e adubação) e um tratamento que recebeu somente a adubação química, com base na recomendação de Vilela et al. (2004). Os tratamentos com gesso também receberam a adição de fertilizantes. O gesso utilizado foi proveniente da indústria de ácido fosfórico, localizada na cidade de Catalão/GO, apresentando a concentração de 180, 150 e 7,5 $\mathrm{g} \mathrm{kg}^{-1}$ de $\mathrm{Ca}$, $\mathrm{S}$ e $\mathrm{P}_{2} \mathrm{O}_{5}$, respectivamente, e umidade de $17 \%$.

No dia 16/10/2012 a forrageira foi rebaixada a uma altura de 0,15 a 0,20 m aproximadamente e foi realizada a demarcação das parcelas experimentais, com tamanho $10 \mathrm{~m}^{2}$. O gesso agrícola foi aplicado manualmente em superfície no dia 30/10/2012 de acordo com os diferentes tratamentos. No dia 17/11/2012, com excessão do tratamento controle, foi realizada a adubação fosfatada na quantidade de $90 \mathrm{~kg} /$ ha de $\mathrm{P}_{2} \mathrm{O}_{5}$, considerando a recomendação para a cultura e a análise de solo. A fonte utilizada foi o superfosfato triplo, com $46 \%$ de $\mathrm{P}_{2} \mathrm{O}_{5}$. A quantidade de $\mathrm{N}$ aplicada foi de 200 $\mathrm{kg} / \mathrm{ha}$, utilizando a ureia como fonte. Essa quantidade foi parcelada em três épocas, sempre após o rebaixamento do pasto, aos 17/11/2012; 21/01/2013 e 15/03/2013.

De acordo com a análise de solo inicial não foi necessário realizar a correção do solo, pois a saturação por bases estava acima do recomendado. Também não foi necessária a correção do solo com potássio.

Para o segundo ano de condução, foi avaliado o efeito residual do gesso agrícola. Com base nos teores médios de $\mathrm{P}$ e Kencontrados no solo (5,1 $\mathrm{mg} \mathrm{dm}^{-3}$ de P e 0,7 $\mathrm{mmol}_{\mathrm{c}} \mathrm{dm}^{-3}$ de K), foi realizada a adubação fosfatada e potássica nas doses de 70 e $40 \mathrm{~kg} /$ ha de $\mathrm{P}_{2} \mathrm{O}_{5}$ e $\mathrm{K}_{2} \mathrm{O}$, respectivamente, no dia $24 / 10 / 2013$. As fontes utilizadas foram o superfosfato triplo e o cloreto de potássio. A adubação nitrogenada, na dose de $200 \mathrm{~kg} / \mathrm{ha}$ (ureia), também foi parcelada em três épocas, aos 24/10/2013,13/12/2013 e 27/02/2014, logo após o rebaixamento da forrageira, esta adubação não foi aplicada apenas no tratamento controle (sem gesso e adubação).

Tanto no primeiro como no segundo ano de condução foram realizados quatro cortes da forrageira, sendo três nas águas e um na seca. Os períodos de avaliação foram distribuídas da seguinte forma para o primeiro ano de condução: janeiro, março e abril para o período das águas e setembro para a avaliação referente ao período seco; para o segundo ano: dezembro, fevereiro e abril (águas), e setembro (seca).

A taxa de cobertura verde do solo (TCV) pela forrageira foi avaliada por meio da análise de imagem digital. As imagens foram obtidas por uma câmera digital, paralelamente a superfície da pastagem em uma mesma altura $(1,6 \mathrm{~m})$, evitando a sombra do fotógrafo ou qualquer outra parte da câmera. Este procedimento proporcionou imagem digital correspondente à área, aproximadamente de $2 \mathrm{~m}^{2}$. Cada figura foi analisada no programa Corel Photo Paint v. 10.410 que permite contar o número de pontos (pixels) de determinada cor de acordo com metodologia adaptada de Godoy et al. (2012). Dessa forma determinou-se a taxa de cobertura verde do solo pelo método da seleção de pixels cor verde.

Para determinação da produtividade a planta forrageira foi coletada com auxílio de uma estrutura de ferro de 1,0 $x$ 0,30 m e cortada com tesoura de aço à altura de $0,20 \mathrm{~m}$, da superfície do solo. Em seguida o material foi pesado (mas- sa fresca) e apenas uma amostra foi acondicionada em sacos de papel e secas em estufa de circulação e renovação de ar forçada por 72 horas na temperatura de $65^{\circ} \mathrm{C}$. Após esse período foi determinada a massa seca da amostra. Após a secagem, as amostras foram moídas e enviadas para o laboratório para a determinação de nutrientes de acordo com a metodologia descrita por Malavolta et al. (1997). A extração dos nutrientes foi calculada multiplicando-se a massa seca da parte aérea da forrageira $(\mathrm{kg} / \mathrm{ha})$ pelo teor do nutriente $(\mathrm{g} / \mathrm{kg})$, considerando em cada ano a média correspondente aos quatro cortes realizados.

Os resultados obtidos foram submetidos à análise de variância para a observação da existência ou não da diferença entre tratamentos. As equações de regressão foram obtidas em função das doses de gesso e a comparação entre as médias das doses de gesso e a adubação química foi comparada pelo teste de Tukey. Os dados amostrados foram analisados utilizando-se o programa Sisvar 4.2. (Ferreira, 2003).

\section{RESULTADOS E DISCUSSÃO}

A TCV pela forrageira foi influenciada pelas doses de gesso em todas as épocas avaliadas, com ajustes quadráticos (Figura 2). No primeiro ciclo as doses es-

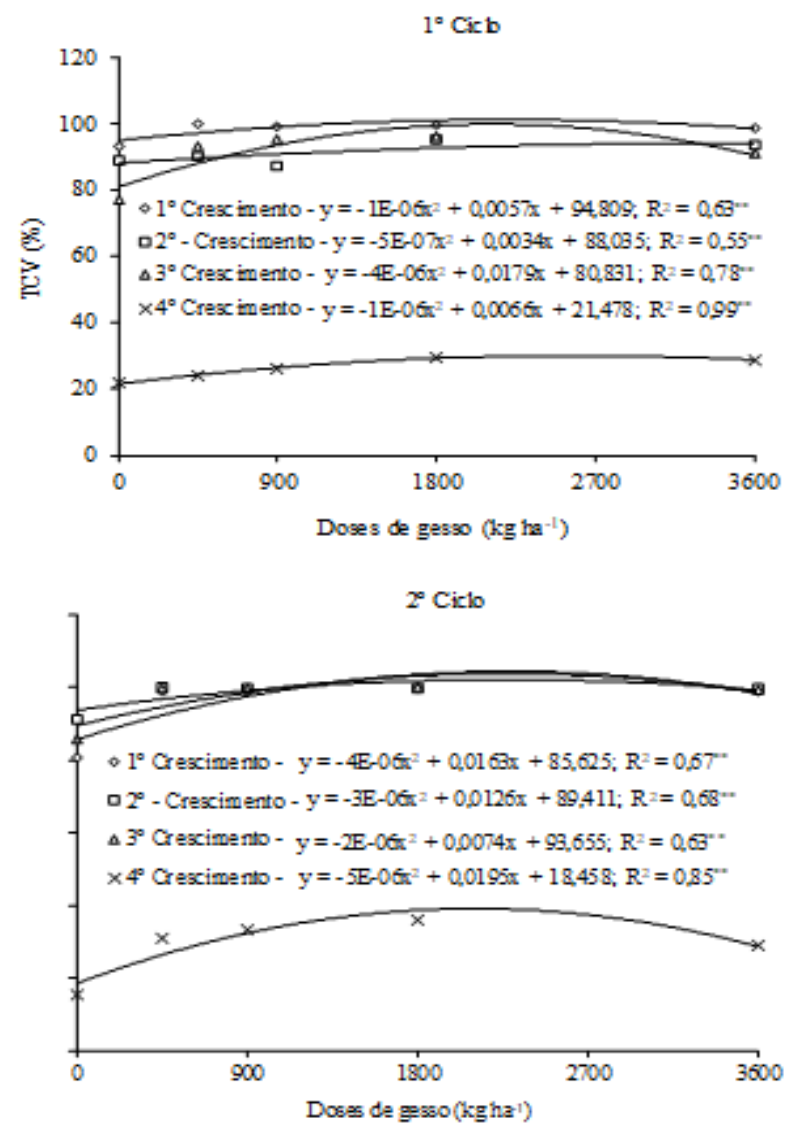

Figura 2. Taxa de cobertura verde do solo pela Uroclhoa brizantha em função de doses de gesso (período das águas, $1^{\circ}, 2^{\circ}$, e $3^{\circ}$ crescimento e seca $4^{\circ}$ crescimento), no primeiro e segundo ciclo. São Luís de Montes Belos/Goiás (Uroclhoa brizantha green soil cover rate in function of plaster doses (water period, 1st, 2nd, and 3rd growth and drought 4th growth) in the first and second cycle. São Luís de Montes Belo/Goiás). 
Tabela I. Taxa de cobertura verde do solo pela Urochloa brizantha em função dos tratamentos (Período das águas, $1^{\circ}, 2^{\circ}$, e $3^{\circ}$ crescimento e seca $4^{\circ}$ crescimento), no primeiro e segundo ciclo. São Luís de Montesbelos $/$ Goiás (Urochloa brizantha green soil cover rate depending on the treatments (water period, $1^{\text {st }}, 2^{\text {nd }}$, and $3^{\text {rd }}$ growth and drought $4^{\text {th }}$ growth), in the first and second cycle. São Luís de Montesbelos/Goiás).

\begin{tabular}{|c|c|c|c|c|c|c|c|c|}
\hline \multirow{4}{*}{ Tratamentos } & \multicolumn{4}{|c|}{ Primeiro ciclo } & \multicolumn{4}{|c|}{ Segundo ciclo } \\
\hline & \multicolumn{3}{|c|}{--------------'Águas------------- } & \multirow[t]{2}{*}{ Seca } & \multicolumn{2}{|c|}{----------------Águas------------- } & \multicolumn{2}{|r|}{ Seca } \\
\hline & \multicolumn{3}{|c|}{ 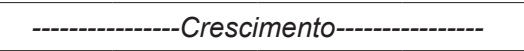 } & & \multicolumn{4}{|c|}{ - - } \\
\hline & $1^{\circ}$ & $2^{\circ}$ & $3^{\circ}$ & $4^{\circ}$ & $1^{\circ}$ & $2^{\circ}$ & $3^{\circ}$ & $4^{\circ}$ \\
\hline & \multicolumn{8}{|c|}{ 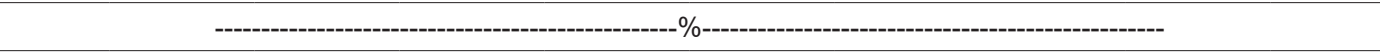 } \\
\hline $0^{*}$ & $93,0^{\mathrm{b}}$ & $89,0^{\mathrm{a}}$ & $77,0^{\mathrm{b}}$ & $21,7 d$ & $80,7^{b}$ & $91,2^{\mathrm{b}}$ & $85,7^{\mathrm{b}}$ & $15,2^{c}$ \\
\hline 450 & $99,7^{\mathrm{a}}$ & $90,0^{\mathrm{a}}$ & $93,0^{\mathrm{a}}$ & $24,1 \mathrm{c}$ & $99,0^{\mathrm{a}}$ & $100,0^{a}$ & $99,5^{\mathrm{a}}$ & $30,7^{\mathrm{ab}}$ \\
\hline 900 & $99,2^{\mathrm{a}}$ & $87,2^{\mathrm{a}}$ & $95,0^{\mathrm{a}}$ & $26,0^{b} \mathrm{C}$ & $98,7^{a}$ & $99,7^{a}$ & $99,7^{a}$ & $33,3^{\text {ab }}$ \\
\hline 1800 & $99,5^{\mathrm{a}}$ & $95,0^{\mathrm{a}}$ & $96,0^{\mathrm{a}}$ & $29,6^{a}$ & $99,5^{\mathrm{a}}$ & $99,7^{a}$ & $100,0^{a}$ & $35,9 a$ \\
\hline 3600 & $98,7^{\mathrm{a}}$ & $93,7^{a}$ & $91,0^{\mathrm{a}}$ & $28,6^{b}$ & $99,0^{a}$ & $99,5^{a}$ & $99,2^{a}$ & $29,1^{a b}$ \\
\hline$A Q$ & $98,7^{\mathrm{a}}$ & $93,0^{\mathrm{a}}$ & $91,0^{\mathrm{a}}$ & $25,3^{b} \mathrm{c}$ & $98,7^{a}$ & $99,7^{a}$ & $99,7^{a}$ & $22,7^{b c}$ \\
\hline CV\% & 1,08 & 3,80 & 3,60 & 4,03 & 0,92 & 0,98 & 2,01 & 16,61 \\
\hline
\end{tabular}

Letras iguais na coluna não diferem entre si pelo teste de Tukey a $5 \%$ de probabilidade. * Doses de Gesso em kg/ha; AQ: adubação química.

timadas de 2850, 3400, 2237 e $3300 \mathrm{~kg} / \mathrm{ha}$ de gesso proporcionaram os maiores valores.

No segundo ciclo as máximas taxas foram obtidas com as doses de 2037, 2100, 1850 e $1950 \mathrm{~kg} / \mathrm{ha}$ de gesso. A TCV expressa o total de área foliar verde por área de superfície do solo ocupada, sendo, portanto, um indicador do desempenho da forrageira em função das condições de manejo e clima.

De acordo com Cantarella e Montezano (2010) a ação do gesso no subsolo permite o aumento da eficiência de uso de outros nutrientes móveis, em especial o N-NO ${ }_{3}^{-}$, o que pode justificar o aumento da TCV do solo pela forrageira. Maiores taxas de forragem verde resultam em maior capacidade fotossintética e maior potencial de acúmulo de açúcar e nutrientes no tecido vegetal, além de possibilitar maior aporte de biomassa, aumentando tanto a disponibilidade quanto a qualidade da pastagem (Mazza et al., 2009).

As menores taxas foram observadas no quarto crescimento (32\% no primeiro ciclo e $37 \%$ no segundo ciclo avaliado). Estas épocas correspondem ao período seco, justificando os resultados obtidos.

Quando comparado o tratamento que recebeu apenas a adubação química verifica-se que, no período das águas, a TCV do solo pela forrageira foi semelhante àquelas que receberam gesso. Apenas o controle apresentou taxas de cobertura menores (Tabela I).

Já no período da seca, o tratamento que recebeu $1800 \mathrm{~kg} / \mathrm{ha}$ de gesso proporcionou melhores resultados. Na maioria das vezes as respostas ao gesso somente são manifestadas em períodos de estiagem e neste caso, a maior taxa de cobertura verde pode ser atribuída ao maior aprofundamento das raízes no subsolo, capazes de absorver água de maior profundidade. Segundo Sousa et al. (2005), a utilização do gesso agrícola proporciona o desenvolvimento das raízes em profundidade ampliando o volume do solo a ser explorado e a tolerância das plantas à seca.
No primeiro ciclo a dose de $1800 \mathrm{~kg} / \mathrm{ha}$ de gesso proporcionou $4,3 \%$ a mais do tratamento que recebeu apenas a adubação química, sendo essa diferença um pouco mais expressiva no segundo ciclo, $13,2 \%$. Segundo Nuernberg et al. (2005) a resposta das plantas ao gesso nem sempre é imediata e muitas vezes são necessários vários anos para que os resultados se tornem significativos.

Verifica-se na Figura 3 que houve influência das doses de gesso na exportação de todos os macronutrientes, com ajustes quadráticos, nos dois ciclos avaliados. A extração dos nutrientes foi grande e cresceu com o aumento da produção de forragem. De acordo com as equações ajustadas as doses de 2085 e $2458 \mathrm{~kg} / \mathrm{ha}$ de gesso proporcionaram as máximas extrações de N (310 e $301 \mathrm{~kg} / \mathrm{ha}$ ). Dentre os nutrientes, o N é um dos mais extraídos pelas gramíneas forrageiras (Primavesi et al., 2006, Costa et al., 2008, Costa et al., 2010a), sendo o responsável pela maior produtividade das mesmas.

A quantidade de $\mathrm{N}$ exportada em cada ciclo foi maior que a quantidade aplicada $(200 \mathrm{~kg} / \mathrm{ha}$ ano-1 $)$. Com a reposição de $\mathrm{N}$ menor que a extração, o nitrogênio aplicado no solo, com o passar do tempo, não será capaz de maximizar a produção de biomassa e o teor de proteínas, o que resultará na diminuição da capacidade de suporte da pastagem. O aumento da produção de massa seca e do teor de proteínas em função do aumento de doses de $\mathrm{N}$ são relatados nos trabalhos de Chagas e Botelho (2005) e Costa et al. (2010b).

As forrageiras do tratamento controle (que não receberam gesso e nem adubação) permitiram uma extração de $125,6 \mathrm{~kg} /$ ha de $\mathrm{N}$ no primeiro ano avaliado, demonstrando a ocorrência de uma ciclagem do nutriente na pastagem instalada a mais de 10 anos, o que se deve a baixa lotação animal na área. No segundo ano avaliado a exportação de $\mathrm{N}$ pela forrageira foi menor, $78,6 \mathrm{~kg} / \mathrm{ha}$, representando $37 \%$ a menos quando comparado ao ciclo anterior. A exportação de $\mathrm{N}$, através da massa seca retirada da área, reduziu a quantidade de matéria orgânica e consequentemente o nitrogênio mineralizável. Magalhães et al. (2002) verificaram que 

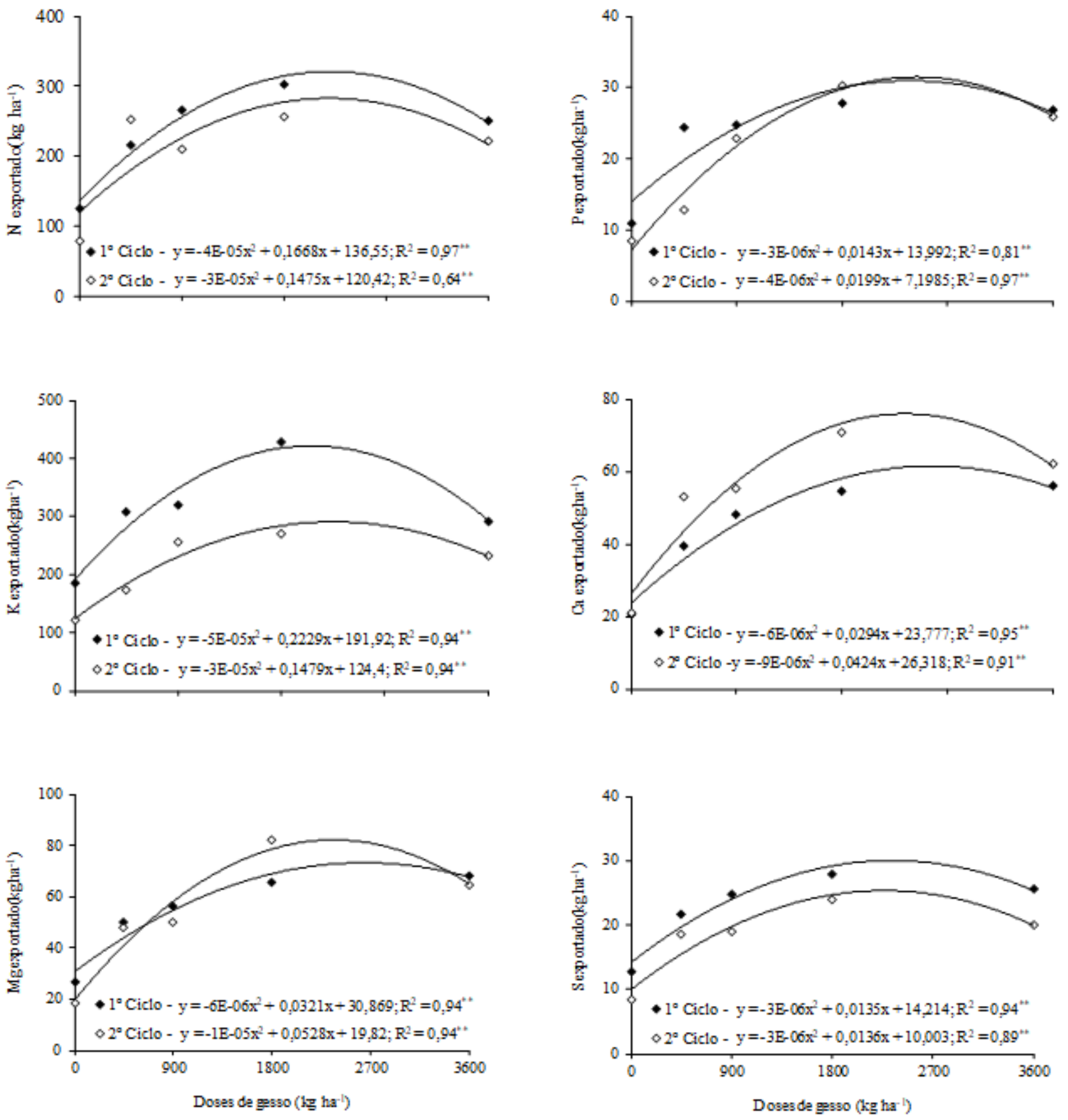

Figura 3. Exportação de macronutrientes na parte aérea da Urochloa brizantha em função de doses de gesso, no primeiro e segundo ciclo. São Luís de Montes Belos/Goiás (Export of macronutrients in the aerial part of the Urochloa Brizantha in function of plaster doses in the first and second cycle. São Luís de Montes Belo/Goiás.

para manter a produtividade no sistema, em função dos nutrientes exportados pela pastagem o nitrogênio da matéria orgânica do solo é insuficiente a partir do quarto ano da instalação.

A quantidade de $\mathrm{P}$ exportada pela forrageira foi de $31 \mathrm{~kg} /$ ha no primeiro ciclo e de $32 \mathrm{~kg} / \mathrm{ha}$ no segundo ciclo avaliado, com as doses estimadas de 2383 e 2487 $\mathrm{kg} /$ ha de gesso, respectivamente. Somando-se o teor de $\mathrm{P}$ inicial no solo $\left(6 \mathrm{mg} \mathrm{dm}^{-3}\right.$, correspondente a 12 $\mathrm{kg} /$ ha de $\mathrm{P}$ ) com a quantidade aplicada no primeiro ciclo $\left(90 \mathrm{~kg} /\right.$ ha de $\left.\mathrm{P}_{2} \mathrm{O}_{5}\right)$, estavam disponíveis para a forrageira $52 \mathrm{~kg} /$ ha de $\mathrm{P}$, demostrando uma eficiência de aproximadamente $60 \%$ na absorção deste nutriente. Deve-se considerar que o fósforo contido no gesso agrícola, como impureza, pode ser importante na nutrição vegetal, no caso de aplicações de doses elevadas de gesso.

As máximas quantidades de $\mathrm{K}$ exportadas pela forrageira foram de 440 e $307 \mathrm{~kg} /$ ha com as doses estimadas de 2229 e $2465 \mathrm{~kg} / \mathrm{ha}$ de gesso. Houve extração bem maior de $\mathrm{K}$ em relação ao $\mathrm{N}$, indicando que o capim-marandu extrai muito K do solo. Resultados semelhantes foram obtidos por Primavesi et al. (2004) ao estudarem a mesma forrageira submetida a doses 
de N. Embora a aplicação de gesso influencie na mobilidade vertical do potássio, doses de até $2465 \mathrm{~kg} / \mathrm{ha}$ neste solo não foram prejudiciais.

$\mathrm{Na}$ instalação do experimento não foi realizada a adubação potássica devido aos teores altos encontrados no solo na camada de $0-20 \mathrm{~cm}\left(3,7 \mathrm{mmol}_{\mathrm{c}} \mathrm{dm}\right.$ ${ }^{3}$, equivalente a $289 \mathrm{~kg} / \mathrm{ha}$ de $\mathrm{K}$ ). Como a pastagem não era adubada a mais de 10 anos, esta quantidade encontrada é atribuída a ciclagem do nutriente pela decomposição das folhas velhas da forrageira. Garcia et al. (2008) verificaram que a Uroclhoa brizantha proporciona uma capacidade considerável de reciclagem $\mathrm{K}$, aumentando seu conteúdo na camada superficial do solo. No segundo ciclo observa-se que os valores de K são bem maiores que o aplicado ao solo pela adubação, mostrando que com a aplicação do gesso, aumentouse a capacidade das raízes dessa forrageira em extrair $\mathrm{K}$ em maiores profundidades do solo, resultando em maior exportação.

Para Ca e Mg as maiores quantidades extraídas foram de 60 e $74 \mathrm{~kg} /$ ha com as doses estimadas de $2450 \mathrm{e}$ $2675 \mathrm{~kg} / \mathrm{ha}$ de gesso respectivamente no primeiro ciclo e de $73 \mathrm{~kg} / \mathrm{ha}$ de Ca e $89 \mathrm{~kg} / \mathrm{ha}$ de $\mathrm{Mg}$ com as doses de 2355 e $2640 \mathrm{~kg} / \mathrm{ha}$ de gesso, respectivamente, no segundo ciclo avaliado. Costa et al. (2008) verificaram que o capim Xaraés, submetido a doses crescentes de $\mathrm{N}$ e $\mathrm{K}$, extraiu mais $\mathrm{Ca}$ que o $\mathrm{Mg}$, diferente do obtido neste trabalho. Mesmo com a aplicação de gesso que é fonte de Ca e de maiores teores de Ca no solo, a extração de $\mathrm{Mg}$ foi maior.

$\mathrm{O}$ aumento de extrações de $\mathrm{Ca}$ e $\mathrm{Mg}$ representa mais de $65 \%$ quando comparados a testemunha. Estes dois nutrientes são absorvidos essencialmente por fluxo de massa e interceptação radicular (Ruiz et al., 1999) e dessa forma o maior desenvolvimento do sistema radicular com a aplicação do gesso pode favorecer a absorção de ambos. Por ser fonte de Ca, o gesso agrícola aplicado proporcionou maiores extrações deste nutriente. A diminuição da extração de $\mathrm{Ca}$ e $\mathrm{Mg}$ na maior dose de gesso pode estar relacionada ao crescimento da planta, pois houve redução da massa seca com a aplicação de $3600 \mathrm{~kg} / \mathrm{ha}$ de gesso.

A extração de enxofre, nos dois ciclos avaliados, foi de 29 e $25 \mathrm{~kg} / \mathrm{ha}$, com as doses estimadas de 2250 e $2267 \mathrm{~kg} /$ ha de gesso, respectivamente. De acordo com Caires et al. (2001), a melhoria do teor de sulfato no perfil do solo é de extrema importância para manter a produtividade de culturas gramíneas, principalmente, em condições de déficit hídrico.

Com a aplicação da dose de $3600 \mathrm{~kg} / \mathrm{ha}$ de gesso pode ter ocorrido maior lixiviação de sulfato para camadas mais profundas do solo. A velocidade com que o sulfato se movimenta é variável em diferentes solos, devendo ser mais lenta em solos com maior teor de argila. Além disso, esta dose proporcionou menor quantidade de massa seca acumulada e o aumento da

Tabela II. Exportação de macronutrientes na parte aérea da Urochloa brizantha em função dos tratamentos, no primeiro e segundo ciclo. São Luís de Montes Belos/Goiás (Export of macronutrients in the aerial part of the Urochloa Brizantha in function of the treatments, in the first and second cycle. São Luís de Montes Belo/Goiás).

\begin{tabular}{|c|c|c|c|c|c|c|}
\hline \multirow{3}{*}{ Tratamentos } & \multicolumn{6}{|c|}{ Primeiro ciclo } \\
\hline & \multicolumn{6}{|c|}{ Macronutrientes } \\
\hline & $\mathrm{N}$ & $\mathrm{P}$ & $\mathrm{K}$ & $\mathrm{Ca}$ & $\mathrm{Mg}$ & $\mathrm{S}$ \\
\hline & \multicolumn{6}{|c|}{ 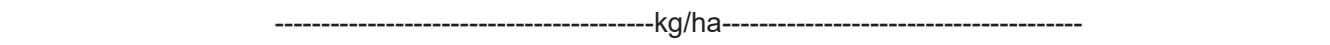 } \\
\hline $0^{*}$ & $125,6 \mathrm{~b}$ & $10,9 \mathrm{c}$ & $185,9 \mathrm{c}$ & $20,5 \mathrm{c}$ & $26,6 \mathrm{~b}$ & $12,7 \mathrm{c}$ \\
\hline 450 & 215,7 a & $24,3 \mathrm{ab}$ & $306,8 \mathrm{abc}$ & $39,3 \mathrm{~b}$ & $49,8 \mathrm{ab}$ & $21,6 a b$ \\
\hline 900 & 264,8 a & $24,8 a b$ & $320,0 \mathrm{ab}$ & $48,3 \mathrm{ab}$ & 56,2 a & $24,8 \mathrm{ab}$ \\
\hline 1800 & 302,8 a & 27,7 a & 428,6 a & $54,6 a b$ & 65,4 a & $27,8 \mathrm{a}$ \\
\hline 3600 & 249,7 a & $26,9 a b$ & $291,5 \mathrm{bc}$ & 56,0 a & $68,3 \mathrm{a}$ & $25,6 a b$ \\
\hline$A Q$ & 222,3 a & $21,3 b$ & $287,6 \mathrm{bc}$ & $41,6 \mathrm{ab}$ & $53,4 \mathrm{a}$ & $19,7 \mathrm{~b}$ \\
\hline \multirow[t]{2}{*}{ CV\% } & 16,81 & 11,63 & 17,86 & 15,44 & 20,59 & 13,67 \\
\hline & \multicolumn{6}{|c|}{ Segundo ciclo } \\
\hline \multirow[t]{2}{*}{ Tratamentos } & \multicolumn{6}{|c|}{ Macronutrientes } \\
\hline & $\mathrm{N}$ & $\mathrm{P}$ & $\mathrm{K}$ & $\mathrm{Ca}$ & $\mathrm{Mg}$ & $\mathrm{S}$ \\
\hline & & \multicolumn{5}{|c|}{ 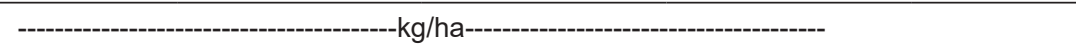 } \\
\hline $0^{*}$ & $78,6 \mathrm{c}$ & $8,5 d$ & $122,5 \mathrm{c}$ & $20,9 \mathrm{c}$ & $18,5 \mathrm{c}$ & $8,3 \mathrm{c}$ \\
\hline 450 & $252,6 \mathrm{ab}$ & $12,8 \mathrm{c}$ & $173,1 \mathrm{~b}$ & $52,9 \mathrm{~b}$ & $48,1 \mathrm{~b}$ & $18,6 \mathrm{~b}$ \\
\hline 900 & $210,4 \mathrm{~b}$ & $22,8 \mathrm{~b}$ & $255,6 \mathrm{ab}$ & $55,3 \mathrm{ab}$ & $49,9 \mathrm{~b}$ & $18,9 \mathrm{~b}$ \\
\hline 1800 & 257,0 a & $30,2 \mathrm{a}$ & $270,5 \mathrm{a}$ & 70,6 a & 81,9 a & 24,0 a \\
\hline 3600 & $221,1 \mathrm{ab}$ & $25,8 \mathrm{~b}$ & $232,7 \mathrm{ab}$ & $62,0 \mathrm{ab}$ & $64,5 \mathrm{ab}$ & $20,1 \mathrm{~b}$ \\
\hline$A Q$ & $216,4 \mathrm{ab}$ & $23,9 \mathrm{~b}$ & $214,7 \mathrm{ab}$ & $61,6 \mathrm{ab}$ & $53,9 \mathrm{~b}$ & $18,4 \mathrm{~b}$ \\
\hline CV\% & 9,45 & 8,88 & 18,58 & 12,80 & 18,07 & 7,68 \\
\hline
\end{tabular}



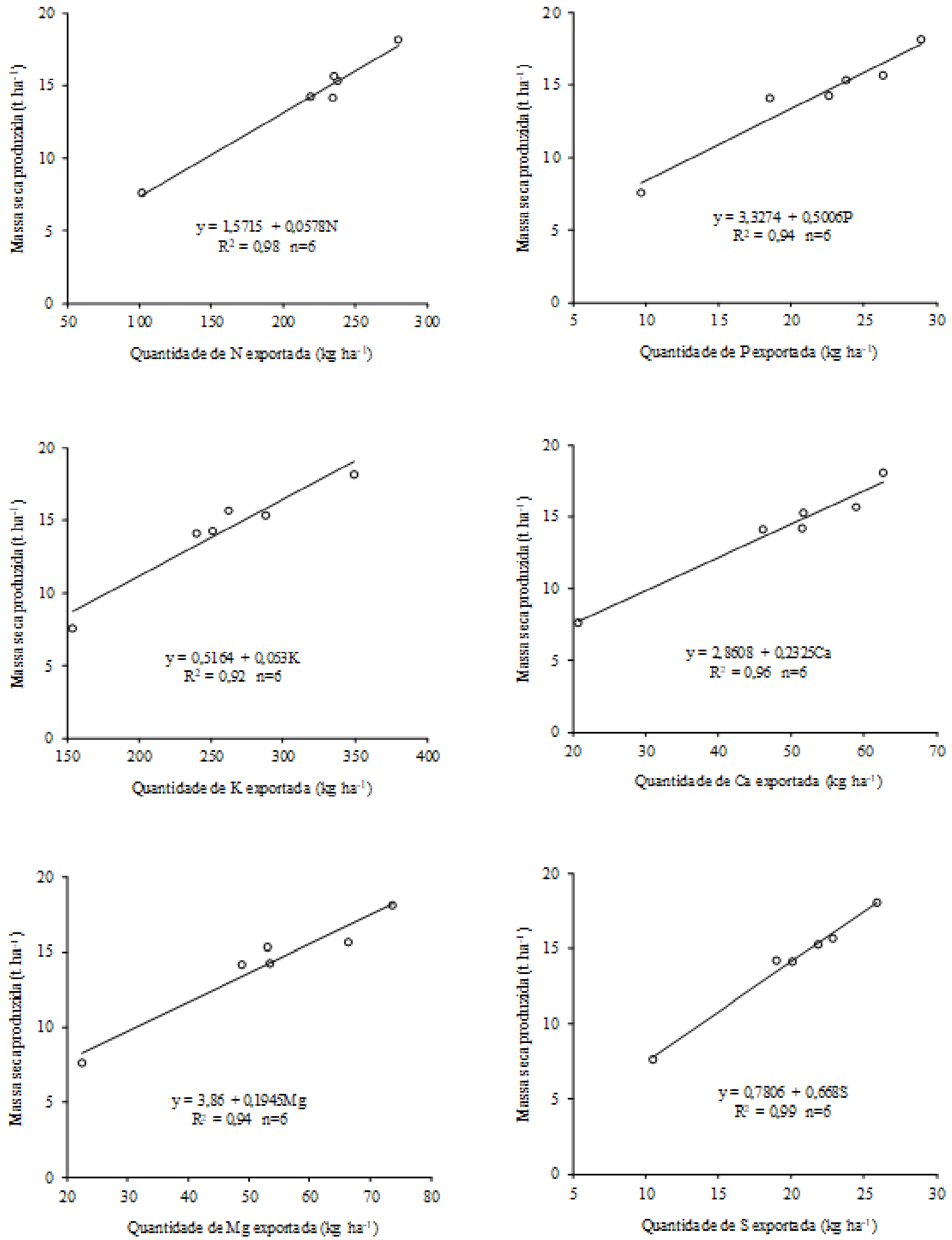

Figura 4. Relação da produtividade de massa seca de Uroclhoa brizantha com as quantidades de N, P, K, Ca, Mg e S exportado do solo, submetida a doses de gesso e adubação química (dados médios de dois anos de produção) (Uroclhoa brizantha dry mass productivity ratio with the quantities of $\mathrm{N}, \mathrm{P}, \mathrm{K}, \mathrm{Ca}, \mathrm{Mg}$ and $\mathrm{S}$ exported from the soil, subjected to plaster doses and chemical fertilization (average data of two years of production). 
extração pode estar diretamente relacionada ao aumento da massa produzida.

Quando comparado as doses de gesso com a adubação química verifica-se no primeiro ciclo, que para o N e Mg exportado não houve diferença estatística. Para P, K, e S a dose de 1800 de gesso proporcionou as maiores exportações. No segundo ciclo a dose de 1800 proporcionou as maiores exportações de todos os macronutrientes avaliados. Este tratamento foi responsável por 16, 21, 21, 13, 34 e $23 \%$ a mais na extração de $\mathrm{N}, \mathrm{P}, \mathrm{K}, \mathrm{Ca}, \mathrm{Mg}$ e S respectivamente, quando comparado ao tratamento que recebeu apenas a adubação química. O maior desenvolvimento do sistema radicular proporcionado pela aplicação do gesso, permite que as plantas utilizem com maior eficiência os nutrientes aplicados no solo (Sousa et al., 2016), ou aqueles disponíveis no solo.

Além de ser fonte de nutrientes como Ca e S, a ação do gesso no subsolo permite o aumento da eficiência de uso de outros nutrientes móveis, em especial o $\mathrm{N}-\mathrm{NO}_{3}^{-}$(Cantarella e Montezano, 2010).

De acordo com Rampim et al. (2013) a aplicação de gesso torna o fósforo mais disponível na camada de 0 a $40 \mathrm{~cm}$ devido a substituição de $\mathrm{H}_{2} \mathrm{PO}_{4}^{-}$por $\mathrm{SO}_{4}{ }^{+2}$. A falta de água disponível faz com que a absorção de $\mathrm{P}$ seja limitada pelo menor coeficiente de difusão no solo.

Ao relacionar a massa seca produzida com a quantidade de nutrientes exportadas da área, verifica-se na Figura 4 que para uma produção média de 10 t ha $^{-1}$ ano ${ }^{1}$ do capim Marandu necessita-se de 146, 13, 179, 31, 32 e $14 \mathrm{~kg} / \mathrm{ha}$ de N, P, K, Ca, Mg e S, respectivamente, ou seja, seriam necessários $14,6 \mathrm{~kg} / \mathrm{ha}$ de N, $1,3 \mathrm{~kg} / \mathrm{ha}$ de P; $17,9 \mathrm{~kg} / \mathrm{ha}$ de $\mathrm{K} ; 3,1 \mathrm{~kg} / \mathrm{ha}$ de Ca; $3,2 \mathrm{~kg} / \mathrm{ha}$ de $\mathrm{Mg}$ e $1,4 \mathrm{~kg} / \mathrm{ha}$ de $\mathrm{S}$ para a produção de $1 \mathrm{t} \mathrm{ha}^{-1}$ ano $^{-1}$ de massa seca da forrageira. Magalhães et al. (2002), avaliando as relações da produção de massa seca com a exportação de nutrientes pelo capim-marandu, verificaram que para a produção de uma tonelada de massa seca foram necessários $10 \mathrm{~kg} / \mathrm{ha}$ de N, 4,6 kg/ha de $\mathrm{P}, 45,4 \mathrm{~kg} / \mathrm{ha}$ de $\mathrm{K}, 3,30 \mathrm{~kg} / \mathrm{ha}$ de Ca e 4,25 kg/ha de $\mathrm{Mg}$. As quantidades de $\mathrm{P}$ e K estimadas pelos autores foram muito superiores aos valores encontrados neste experimento.

Vale ressaltar que não está sendo considerada às perdas dos nutrientes no sistema, que dependerão das condições climáticas, tipos de solos e fontes utilizadas. De acordo com Alcarde (1998) o aproveitamento dos nutrientes aplicados estão na faixa de 70 a $90 \%$ para o N, 5 a $20 \%$ para o P e de 50 a $70 \%$ para o K. Ao relacionar a extração de nutrientes pela forrageira com o que foi adicionado via fertilizantes observa-se que esta eficiência foi maior, o que pode ser atribuído a prática da gessagem, que ao proporcionar melhoria do ambiente radicular, promove maior aprofundamento das raízes e consequentemente a absorção de nutrientes de camadas mais profundas do solo.

\section{CONCLUSÕES}

O gesso promoveu aumento da taxa de cobertura verde do solo pela forrageira, principalmente no período da seca.
A ordem decrescente de extração para o capimmarandu, considerando extração máxima de cada nutriente, foi: $\mathrm{K}>\mathrm{N}>\mathrm{Mg}>\mathrm{Ca}>\mathrm{P}>\mathrm{S}$.

Para uma produção média de $10 \mathrm{tha}^{-1} \mathrm{ano}^{-1}$ do capim Marandu necessita-se de 146, 13, 179, 31, 32 e 14 $\mathrm{kg} /$ ha de N, P, K, Ca, Mg e S, respectivamente.

\section{BIBLIOGRAFIA}

Alcarde, JC, Guidolin, JA \& Lopes, AS 1998, Boletim Técnico n 3: Os adubos e a eficiencia das adubações, visualizado 09 janeiro 2017, <http://www.anda.org.br/multimidia/boletim_03.pdfs.

Caires, EF, Feldhaus, IC \&Blum, J 2001, Crescimento radicular e nutrição da cevada em função da calagem e aplicação de gesso. Bragantia, vol. 60, no. 3, pp.213-223.

Cantarella, H \& Montezano, ZF 2010, 'Nitrogênio e enxofre'. In LI Prochnow, V Casarin, SR Stipp (eds.), Boas práticas para uso eficiente de fertilizantes: Nutrientes, IPNI, Piracicaba, São Paulo, Brasil, pp. 1 - 65.

Chagas, LAC \& Botelho, SMS 2005 Teor de proteína bruta e produção de massa seca do capim-braquiária sob doses de nitrogênio, Bioscience jornal, vol. 21, no. 1, pp. 35-40.

Costa, KAP, Araujo, JL, Faquim, V, Oliveira, I P, Figueiredo, FC \& Gomes, KW 2008, Extração de macronutrientes pela a fitomassa do capim-xaraés "xaraés" em função das doses de nitrogênio e potássio, Ciência Rural, vol. 38, no. 4, pp.1162-1166.

Costa, KAP, Oliveira, IP, Severiano, EC, Sampaio, FMT, Carrijo, MS \& Rodrigues, CR 2010a, Extração de nutrientes pela fitomassa de cultivares de Brachiaria brizantha sob doses de nitrogênio, Ciência Animal Brasileira, vol. 11, no. 2, pp. 307-314.

Costa, KAP, Faquin, V \& Oliveira, IP 2010b. Doses e fontes de nitrogênio na recuperação de pastagens do capim-marandu. Arquivos Brasileiro de Medicina Veterinaria e Zootecnia, vol. 62, no. 1, pp. 192-199.

Echart, CL \& Cavalli-Molina, S 2001, Fitotoxidade do alumínio: efeitos, mecanismos de tolerancia e seu controle genético, Ciência Rural, vol. 31 , no. 3, pp. 531-541

Embrapa, 2013, Sistema brasileiro de classificação de solos, 3ed, Brasília, Brasil: Embrapa. p. 353.

Garcia, RA, Crusciol, CAC, Calonego, JC. \& Rosolem, CA 2008, Potassium cycling in a corn-brachiaria cropping system. European Journal of Agronomy, vol. 28, no. 4, pp. 579-585.

Guelfi, DR, Faquin, V, Souza, MAS, Oliveira, GC, Santoucy, SG \& Bastos, CEA 2013, Características estruturais e produtivas do capim-marandu sob efeitos de corretivos da acidez, gesso e compactação do solo. Interciencia, vol.38, no. 9, pp. 681-687.

Lopes, AA \& Guilherme, LRG 2000, Uso eficiente de fertilizantes e corretivos agrícolas: aspectos agrônomicos, 3 rd edn, ANDA, São Paulo, Brasil.

Magalhães, RT, Oliveira, IP \& Kliemann, HJ 2002, Relações de produção de massa seca e as quantidades de mutrientes exportados por Brachiaria brizantha em solos sob o manejo pelo sistema Barreirão, Pesquisa Agropecuária Tropical, vol. 32, no. 1, pp.13-20.

Malavolta, E, Vitti, GC, Oliveira, SA 1997, Avaliação do estado nutricional das plantas: princípios e aplicações. 2rd edn, Associação Brasileira da Potassa e do Fosfato, Piracicaba, São Paulo, Brasil.

Mazza, LM, Pôggere, GC, Ferraro, FP, Ribeiro, CB, Cherobim, VF, Motta, ACV \& Moraes, A 2009. Adubação nitrogenada na produtividade $e$ composição química do capim mombaça no primeiro planalto paranaense. Scientia Agrária, vol. 10, no. 4, pp.257-265.

Nuernberg, NJ, Rech, TD \&Basso, C2005, Boletim Técnico no 122: Uso do gesso agrícola. 2rd edn, Epagri, Florianopolis, Santa Catarina, Brasil.

Primavesi, AC, Primavesi, O, Corrêa, LA, Cantarella, H, Silva, AG, Freitas, AR \& Vivaldi, L.F. 2004, Adubação nitrogenada em Capim-Coastcross: efeitos na extração de nutrientes e recuperação aparente do nitrogênio. Revista Brasileira de Zootecnia, vol. 33, no. 1, pp. 68-78.

Primavesi, AC, Primavesi, O, Corrêa, LA, Silva, AG \& Cantarella, H 2006. Nutrientes na fitomassa de capim-marandu em função de 
fontes e doses de nitrogênio. Ciência e Agrotecnologia, vol. 30, no. 3, pp. 562-568.

Raii, B, Furlani, PR., Quaggio, J.A \& Pettinelli Júnior, A 1998, Gesso na produção de cultivares de milho com tolerância diferencial a alumínio em três níveis de calagem, Revista Brasileira de Ciência do Solo, vol. 22, no.1, pp. 101-108.

Rampim, L, Lana, MC \& Fradoloso, JF 2013, Fósforo e enxofre disponível, aluminio trocável e fósforo remanescente em latossolo vermelho submetido ao gesso cultivado com trigo e soja. Semina: Ciências Agrárias, vol. 34, no.4, pp. 1623 - 1638.

Ruiz, HA, Miranda, J \& Conceição, JCS 1999, Contribuição dos mecanismos de fluxo de massa e de difusão para o suprimento de K, Ca e Mg a plantas de arroz. Revista. Brasileira de Ciência do Solo, vol. 23, no. 4, pp.1015-1018.

Santos, JR, Bicudo, SJ, Nakagawa, J, Albuquerque, AW \& Cardoso, CL 2006, Atributos químicos do solo e produtividade do milho afetados por corretivos e manejo do solo. Revista Brasileira de Engenharia Agrícola e Ambiental, vol. 10, no. 2, pp.323-330.

Silva, DRG, Costa, KAP, Faquin, V, Oliveira, IP \& Bernardes, TF 2013, Rates and sources of nitrogen in the recovery of the structural and productive characteristics of marandu grass. Revista Ciência Agronômica, vol. 44, no. 1, pp. 184-191.
Sousa, DMG, Nunes, RS, Rein, TA, Santos Junior, JDG \& Oliveira, SA 2016, 'Acidez do solo e sua correção na região do cerrado', in RA Flores \& PP Cunha (eds.), Práticas de Manejo do Solo para Adequada Nutrição de Plantas no Cerrado. Gráfica UFG, Goiânia, Goiás, Brasil cap. 5, pp. 124-190.

DMG Sousa \& E Lobato 2004. Correção da acidez do solo, in Sousa, DMG, Lobato, E (eds.) Cerrado: correção do solo e adubação, Embrapa cerrados, Planaltina, Distrito Federal, Brasil, pp.147-168. Sousa, D MG, Lobato, E, Rein, TA 2005, Circular Técnica no 32: Uso de gesso agrícola nos solos do Cerrado, Embrapa Cerrados, Planaltina, Distrito Federal.

Valle, CB, Jank, L \& Resende, RMS 2009, O Melhoramento de Forrageiras Tropical no Brasil, Revista Ceres, vol. 54, no. 4, pp. 460-472.

Vilela, L, Soares, WV, Sousa, DMG \& Macedo, MCM 2004, 'Calagem e adubação para pastagens', in DMG Sousa \& E Lobato (eds.), Cerrado: correção do solo e adubação. Embrapa Cerrados, Planaltina, Distrito Federal, Brasil, pp.147-168.

Vitti, CG, Luz, PHC, Malavolta, E, Dias, AS \& Serrano, CGE 2008, Uso do gesso em sistemas de produção agrícola. GAPE, Piracicaba, São Paulo, Brasil. 